\title{
Therapeutic efficacy of ozenoxacin in animal models of dermal infection with Staphylococcus aureus
}

\author{
Cristina Tarragó ${ }^{1}$, Lluís Pérez Esquirol ${ }^{2}$, Antònia Arañó ${ }^{2}$, Laurence Lachamp ${ }^{3}$, Fabiana \\ D'Aniello 4 \& Ilonka Zsolt*,5 \\ ${ }^{1}$ Spherium Biomed, Barcelona, Spain \\ ${ }^{2}$ Centro de Investigación y Desarrollo Aplicado, SAL (CIDASAL), Barcelona, Spain \\ ${ }^{3}$ Ascil Biopharm, Business Innovation Director, Barcelona, Spain \\ ${ }^{4}$ Business Development \& Innovation Department, Ferrer Internacional, Barcelona, Spain \\ ${ }^{5}$ Medical Department, Ferrer Internacional, Barcelona, Spain \\ *Author for correspondence: izsolt@ferrer.com
}

\begin{abstract}
Aim: To assess different concentrations and formulations of topical ozenoxacin using a mouse model of Staphylococcus aureus dermal infection for identification of the best formulation for treating patients with impetigo. Materials \& methods: The efficacy of ozenoxacin formulations was compared with vehicle control, mupirocin and retapamulin ointments in a mouse model. Results: The most effective concentrations of ozenoxacin for reducing $S$. aureus counts after dermal application were 1 and $2 \%$. Direct comparison of two batches of $1 \%$ ozenoxacin ointment and cream with $1 \%$ retapamulin and $2 \%$ mupirocin ointments in the mouse model showed superior efficacy of ozenoxacin. Conclusion: $1 \%$ ozenoxacin ointment and cream were the most effective formulations in significantly reducing bacterial load in $S$. aureus dermally infected mice.
\end{abstract}

First draft submitted: 4 December 2017; Accepted for publication: 16 March 2018; Published online: 10 May 2018

Keywords: animal models $\bullet$ dermal infection $\bullet$ impetigo $\bullet$ ozenoxacin $\bullet$ Staphylococcus aureus

Ozenoxacin is a nonfluorinated topical quinolone that was recently approved for the treatment of impetigo in adults and children. It has potent in vitro bactericidal activity against a range of Gram-positive bacteria including pathogens which cause skin infections such as impetigo [1-8]. Actions include potent antibacterial activity against strains that are resistant to fusidic acid and/or mupirocin [2] and to other quinolones such as levofloxacin and ciprofloxacin [3-5].

Staphylococcus aureus is the most frequently isolated pathogen from cases of impetigo [9], and causes both nonbullous and bullous forms of the disease [9-11]. As part of the development program for ozenoxacin as a topical treatment for impetigo, a mouse model of $S$. aureus dermal infection was used to compare different concentrations and formulations of topically applied ozenoxacin in order to select the optimal formulation. In all cases, comparisons were made against topical mupirocin and/or retapamulin, which are currently marketed antibiotics for topical treatment of impetigo [12].

The clinical efficacy of ozenoxacin for treating impetigo was shown subsequently in Phase III trials [13,14]. Ozenoxacin $1 \%$ cream has received regulatory approval and is indicated for the topical treatment of impetigo in children and adults [15-17].

\section{Materials \& methods}

A mouse model of wound infection, using $S$. aureus as the infective agent, was used to compare different concentrations of ozenoxacin formulations and patterns of administration. The methods used were based on the $S$. aureus-infected suture mouse model described by Gisby and Bryant [18]. 


\section{Infection of suture threads with Staphylococcus aureus}

Suture threads were infected by immersion for $30 \mathrm{~min}$ in an overnight culture of $S$. aureus CECT 239 (ATCC 6538), which was diluted to a concentration of approximately $10^{8}$ colony-forming units (CFU)/ml following spectrophotometric measurement. The threads were removed and dried on filter paper. Two 1-cm lengths were cut from each suture thread and each was vortexed in a tube containing $1 \mathrm{ml}$ of $0.2 \%$ yeast extract. Dilutions were made of these broths and transferred, in duplicate and in parallel, to cysteine-, lactose-, and electrolyte-deficient (CLED) agar plates to ascertain the density of $S$. aureus on the suture threads. The remainder of the suture threads were kept in a refrigerator until use.

In the summarized studies, the mean $\log _{10}$ transformed CFU/100 $\mu \mathrm{l}$ of $S$. aureus on the threads used to infect the animals was between 4.2 and 5.0 .

With each formulation tested, the first treatment dose was applied $4 \mathrm{~h}$ after incision and dermal infection of the animals. Different management patterns were used, ranging from a single application to three administrations per day for 4 days.

Each treatment was applied topically to the affected area in a volume of approximately $0.1 \mathrm{ml}$ per animal. Massage of $\geq 30 \mathrm{~s}$ was performed with the fingertip to facilitate and homogenize product absorption.

In each study, clinical signs including body weight were evaluated. The area surrounding the lesion and fur growth was continuously assessed by visual observation, and total $S$. aureus load was tested (see 'Microbiological analyses' section) at the end of the studies.

\section{Mouse model of dermal infection with S. aureus}

CD-1 ${ }^{\circledR}$ mice, approximately 4 weeks old, were obtained from Harlan Laboratories Interfauna SL (Barcelona, Spain). Animals were fed with a standard rodent maintenance diet and received water ad libitum.

The day before the start of the experiment, the animals were shaved and depilated with a commercial depilatory cream. On experimental day 1 , mice were anesthetized with sodium pentobarbital $(50 \mathrm{mg} / \mathrm{kg}$; study I) or isoflurane (studies II and III) and dermally infected using a needle threaded with silk suture thread, which was previously infected with a high and controlled inoculum of $S$. aureus (values are shown below for each study). A puncture wound was made which pierced the skin at the height of the shoulder girdle with the exit wound being approximately $1 \mathrm{~cm}$ below. Knots were tied at each end of the thread to ensure that its subcutaneous position was maintained. A superficial incision was then made with a scalpel between both knots, without reaching the panniculus carnosus.

Ozenoxacin, mupirocin, retapamulin and vehicle formulations were applied to the infected area in each study. Mupirocin (2\%) ointment acted as a positive control for all experiments. Retapamulin (1\%) ointment was used as comparator in one study (study III), and a pharmacologically inactive formulation (vehicle control) was used as a negative control in each study. Excipients in ozenoxacin 1\% cream are benzoic acid (E 210), ethylene glycol monopalmitostearate, octyldodecanol, oleoyl macrogol-6-glycerides, polyethylene glycol-6 stearate, polyethylene glycol-32 stearate, propylene glycol, purified water and stearyl alcohol [15-17].

Treatments were applied topically $(0.1 \mathrm{ml} / \mathrm{animal})$ by massaging the infected area for a minimum of $30 \mathrm{~s}$. Dosing schedules are indicated in the relevant sections below. Mice were randomly assigned to each treatment group $(\mathrm{n}=15)$.

\section{Study I: antibacterial activity of different formulations of ozenoxacin (1\%) in a mouse model of S. aureus dermal infection}

The objective of study I was to identify the most effective $1 \%$ ozenoxacin formulation in mice dermally infected with $S$. aureus. Five different formulations of ozenoxacin (1\%) were compared: an ointment (batch 1), two batches of gel (batches 2 and 3) and two batches of cream (batches 4 and 5); together with mupirocin (2\%) ointment and vehicle control ointment. Treatments were applied once daily for 3 days. On day 4, approximately $20 \mathrm{~h}$ after the last treatment, mice were sacrificed and skin samples were excised for microbiological counts (details in the 'Microbiological analyses' section).

The mean \pm standard error of the mean (SEM) $\log _{10}$ transformed CFU/100 $\mu \mathrm{l}$ of S. aureus on the threads $(\mathrm{n}=27)$ used for dermal infection of mice in study I (determined by growth on CLED agar plates) was $4.47 \pm 0.054$. Corresponding counts for $S$. aureus grown on CLED agar $+50 \mathrm{mM} \mathrm{MgCl}\left(\mathrm{CLED}-\mathrm{MgCl}_{2}\right)$ and CLED agar $+2 \%$ activated charcoal (CLED-AC) plates were $4.51 \pm 0.054$ and $4.54 \pm 0.057$, respectively. 


\section{Study II: dose-effect antibacterial activity of ozenoxacin ointment in a mouse model of S. aureus dermal infection}

In study II, the objective was to identify the minimal ozenoxacin concentration in an ointment formulation that was effective in reducing dermal bacterial infection. Comparisons of the antibacterial effects of different doses of ozenoxacin ointment $(0.25,0.50,1$ and $2 \%)$ were made, together with mupirocin (2\%), and vehicle control ointments. All treatments were applied once, $4 \mathrm{~h}$ after dermal infection, and microbiological counts were performed $16 \mathrm{~h}$ after the application. This single treatment design aimed to identify the quickest and most potent antibacterial action.

The mean $\pm S E M \log _{10}$ transformed CFU/100 $\mu$ of $S$. aureus on the threads $(\mathrm{n}=8)$ used for dermal infection of mice in study II (determined by growth on CLED agar plates) was $4.98 \pm 0.077$.

Study III: comparison of the antibacterial activity of ozenoxacin (1\%) ointment \& cream with reptamulin (1\%) \& mupirocin (2\%) ointments in a mouse model of S. aureus dermal infection

The objective of this study was to compare two different batches of ozenoxacin $1 \%$ formulations (cream and ointment), selected in the previous study due their highest efficacy, with retapamulin $1 \%$ and mupirocin $2 \%$ ointments, the current marketed topical antibiotics to treat impetigo. As in study II, treatments were applied once, $4 \mathrm{~h}$ after dermal infection, in order to identify the quickest and most potent antibacterial agent. Animals were sacrificed $16 \mathrm{~h}$ after treatment, and microbiological counts were performed in excised skin samples.

The mean \pm SEM $\log _{10}$ transformed CFU/100 $\mu$ l of $S$. aureus on threads $(n=15)$ used for dermal infection of mice in study III (determined by growth on CLED agar plates) was $5.01 \pm 0.038$.

\section{Microbiological analyses}

At the designated end of the treatment period (minimum $16 \mathrm{~h}$ after the last administration), animals were sacrificed by cervical dislocation. An area of skin, approximately $1-2 \mathrm{~cm}$ which included the wound, was removed and weighed. Skin samples were homogenized in $5 \mathrm{ml}$ of physiological saline, and each sample was serially diluted using stepwise $1: 10$ dilutions, to a final dilution of $1: 100$ or 1:1000. Using $0.1 \mathrm{ml}$ volumes, the dilutions were plated in parallel onto three types of agar plate. CLED agar plates were used to count colonies for comparison of all experimental groups, while CLED- $\mathrm{MgCl}_{2}$ or CLED-AC plates were used to prevent antibiotic carryover during the incubation period. CLED- $\mathrm{MgCl}_{2}$ plates were used for colony counts of animals treated with different formulations of ozenoxacin, as previously recommended [1]. CLED-AC plates were used for colony counts in animals treated with mupirocin, as recommended [18], and for retapamulin treatment. Plates with counts of 15-150 CFU/plate were used for subsequent calculations, following standard microbiological procedures.

Raw microbiological count data (CFU/plate) were initially converted into CFU per unit weight of skin, taking into account prior dilutions, the weight (in grams) of the skin samples and the volume ( $5 \mathrm{ml}$ ) of saline used for tissue homogenization:

$\mathrm{CFU} / \mathrm{g}$ skin $=(\mathrm{CFU} /$ plate $) \times($ dilution $) \times(5 \mathrm{ml} / \mathrm{g}$ skin sample $)$.

$\log _{10}$ transformation of CFU/g skin data from vehicle control and test treatments of animals was used to compare the efficacy of different treatments.

The lower limit of detection was approximately $10^{2} \mathrm{CFU} / \mathrm{g}$ skin sample in all performed experiments. Therefore, the number of skin samples with low/zero bacterial recovery was an important consideration to highlight the efficacy of dermal formulations in the eradication of bacterial load in the skin [19].

In study III, where experimental conditions allowed, $\log _{10}$ transformations of CFU/g skin data from vehicle control and test treatments of animals were also used to calculate the $\%$ bacterial eradication rate as follows:

$$
\% \text { bacterial eradication rate }=\frac{\left[\log _{10}(\mathrm{CFU} / \mathrm{g} \text { skin })_{\text {control }}-\log _{10}(\mathrm{CFU} / \mathrm{g} \text { skin })_{\text {test }}\right]}{\log _{10}(\mathrm{CFU} / \mathrm{g} \text { skin })_{\text {control }}} \times 100
$$

\section{Efficacy measures \& statistical analyses}

In each study, results of each treatment were compared with those of the control group treated with a placebo (vehicle control) formulation. Comparisons were made between groups treated with ozenoxacin formulations and the comparative antibiotics, mupirocin and retapamulin, as well as between groups treated with different formulations 
Table 1. Number of animals per treatment group with a viable microbiological count below the limit of detection (approximately $10^{2} \mathrm{CFU} / \mathrm{ml}$; study I).

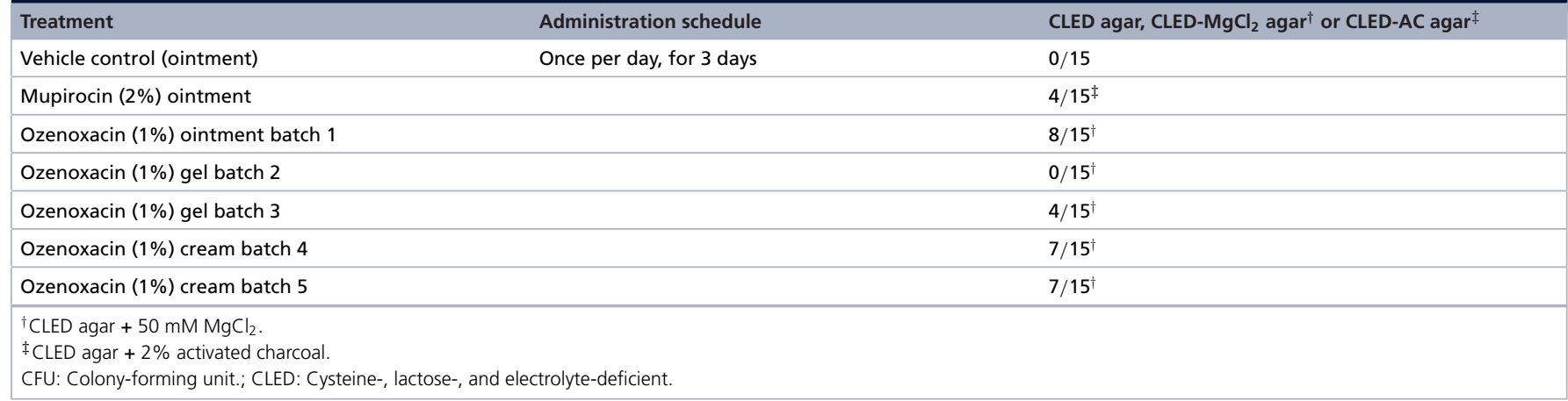

of ozenoxacin. Depending on the normality of the population, parametric statistical tests (Tukey's honest significant difference [HSD] or Student's $t$-test) or nonparametric (Kruskal-Wallis test) were used. Differences between clinical signs or adverse effects detected between groups were analyzed using Pearson $\chi^{2}$ test, with a significance level of $5 \%$.

Efficacy results of the three animal studies were based on bacterial counts obtained in the lesion area extirpated from each animal after topical treatment of the skin. Values \pm SEM are expressed as the logarithm base 10 of the arithmetic mean of colony forming units per gram of skin.

The mean initial infective inoculum was approximately $2 \times 10^{5} \mathrm{CFU} / \mathrm{cm}^{2}$. This was the concentration of bacterial load on the thread inserted sub-dermally. The infection, once established, will decrease to a greater or lesser extent, depending on the antibacterial efficacy of the different formulations applied, and the daily administration schedule.

\section{Results}

Study I: antibacterial activity of different formulations of $1 \%$ ozenoxacin in a mouse model of dermal infection with $S$. aureus

In the control group, mean $\pm S E M \log _{10}(\mathrm{CFU} / \mathrm{g}$ skin) counts following plating on CLED agar were 6.46 \pm 0.187. In the mupirocin $2 \%$ group, $\log _{10}(\mathrm{CFU} / \mathrm{g}$ skin) counts were $3.95 \pm 0.290$ following plating on CLED-AC. $\log _{10}(\mathrm{CFU} / \mathrm{g}$ skin) counts for five ozenoxacin $1 \%$ batches following plating on CLED-MgCl 2 were $3.00 \pm 0.258$ (ointment batch 1); $3.54 \pm 0.222$ and $3.34 \pm 0.238$ (gels: batches 2 and 3, respectively); and $3.16 \pm 0.264$ and $3.37 \pm 0.313$ (creams: batches 4 and 5, respectively).

As the values of $\log _{10}(\mathrm{CFU} / \mathrm{g}$ skin) obtained did not follow a normal distribution (homogeneity test for variance; $\mathrm{p}<0.01$ ), the Kruskal-Wallis test was performed, and statistically significant differences were observed (Pearson's $\chi^{2}$ test; $\left.\mathrm{p}<0.01\right)$. Counts obtained on CLED agar, on CLED- $\mathrm{MgCl}_{2}$ and on CLED-AC for all treatment groups were significantly lower compared with the control group (Tukey's HDS test; $\mathrm{p}<0.05$ ). The means of each treatment were ordered, using Tukey's HDS test, from lowest to highest value: ozenoxacin $1 \%$ ointment batch 1, cream batch 4, gel batch 3, cream batch 5, gel batch 2 and mupirocin ointment. No statistically significant differences between different formulations of the test item ozenoxacin $1 \%$ were observed for efficacy.

Growth of $S$. aureus was observed on the three types of agar plates derived from all skin samples treated with the vehicle control (ointment; $\mathrm{n}=15$ ). Growth of $S$. aureus was also observed on CLED- $\mathrm{MgCl}_{2}$ plates in all skin samples treated with $1 \%$ ozenoxacin batch 2 gel $(n=15)$, which produced the highest mean bacterial counts $(3.54 \pm 0.222)$ of all ozenoxacin treatment formulations. There was no growth of $S$. aureus plated on CLED- $\mathrm{MgCl}_{2}$ in skin samples from some animals treated with three of four formulations of ozenoxacin $(1 \%)$ tested: in batches $1(n=8), 4(n=7)$ and 5 ( $\mathrm{n}=7$; Table 1$)$.

In summary, comparison of five different $1 \%$ ozenoxacin formulations ( 1 ointment, 2 gels and 2 creams) showed that each formulation significantly reduced the bacterial count compared with the negative vehicle control group, with no significant differences between formulations. Similarly, there were no significant differences between $2 \%$ mupirocin ointment and any of the $1 \%$ ozenoxacin formulations (Figure 1). However, the most effective formulations were $1 \%$ ozenoxacin cream (batch 4 ) and ointment (batch 1; Tukey's HSD test; $\mathrm{p}<0.05$ ). 


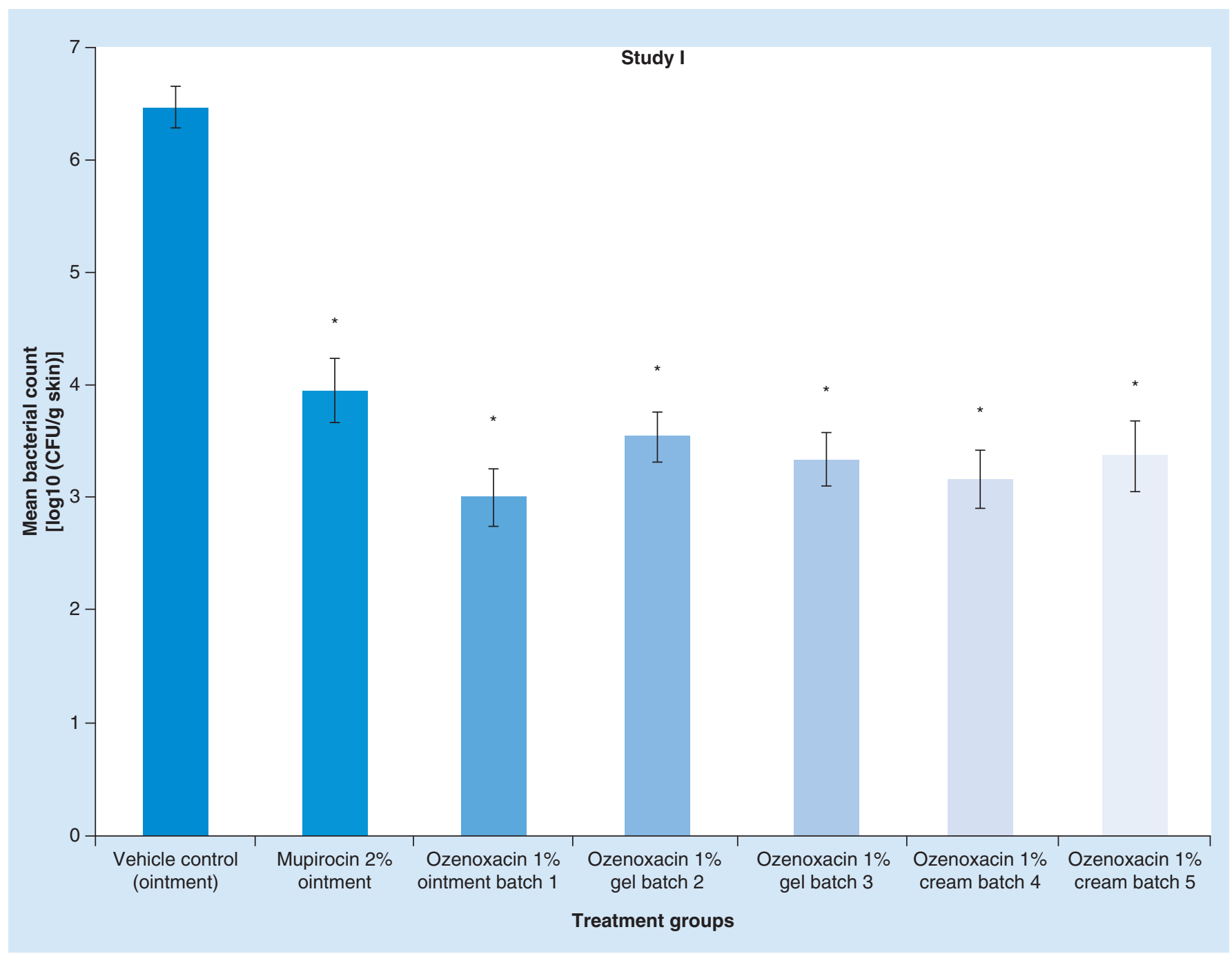

Figure 1. Mean bacterial counts in mice treated with ozenoxacin $1 \%$, mupirocin $2 \%$ or vehicle control ointment administered once per day, for 3 days (study I).

*Tukey's HSD test $p<0.05$ for comparison of treatment groups with vehicle control.

CFU: Colony-forming unit.

Study II: dose-effect antibacterial activity of ozenoxacin ointment in a mouse model of dermal infection with $S$. aureus

In the placebo group, mean \pm SEM $\log _{10}(\mathrm{CFU} / \mathrm{g}$ skin) counts were $6.63 \pm 0.127$ following plating on CLED agar. In the mupirocin $2 \%$ ointment group, $\log _{10}(\mathrm{CFU} / \mathrm{g}$ skin) counts were $4.57 \pm 0.192$ following plating on CLED-AC. In the four ozenoxacin ointment batches tested, $\log _{10}$ (CFU/g skin) counts (following plating on CLED- $\mathrm{MgCl}_{2}$ ), were $4.98 \pm 0.231$ (0.25\% ozenoxacin), $4.17 \pm 0.335$ (0.5\% ozenoxacin), $3.49 \pm 0.237$ (1\% ozenoxacin) and $3.31 \pm 0.235$ ( $2 \%$ ozenoxacin).

The Kruskal-Wallis test was performed and statistically significant differences were observed between treatment groups ( $\mathrm{p}<0.001$ ). Analyses of between-group differences using Tukey's HSD test showed that topically applied ozenoxacin ointment $(0.25,0.5,1$ and $2 \%)$ and mupirocin ointment (positive control) produced a statistically significant reduction $(\mathrm{p}<0.05)$ in bacterial growth compared with the pharmacologically inactive vehicle control ointment (Figure 2). Additionally, mice treated with 1 or $2 \%$ ozenoxacin ointment showed statistically significant reductions (Tukey's HSD test; $\mathrm{p}<0.05$ ) in counts compared with the $2 \%$ mupirocin ointment group (Figure 2 ).

A clear dose-effect relationship was found with ozenoxacin at the concentrations used, with 1 and $2 \%$ ozenoxacin ointments being the most effective. These results were observed irrespective of the culture media used (CLED or 


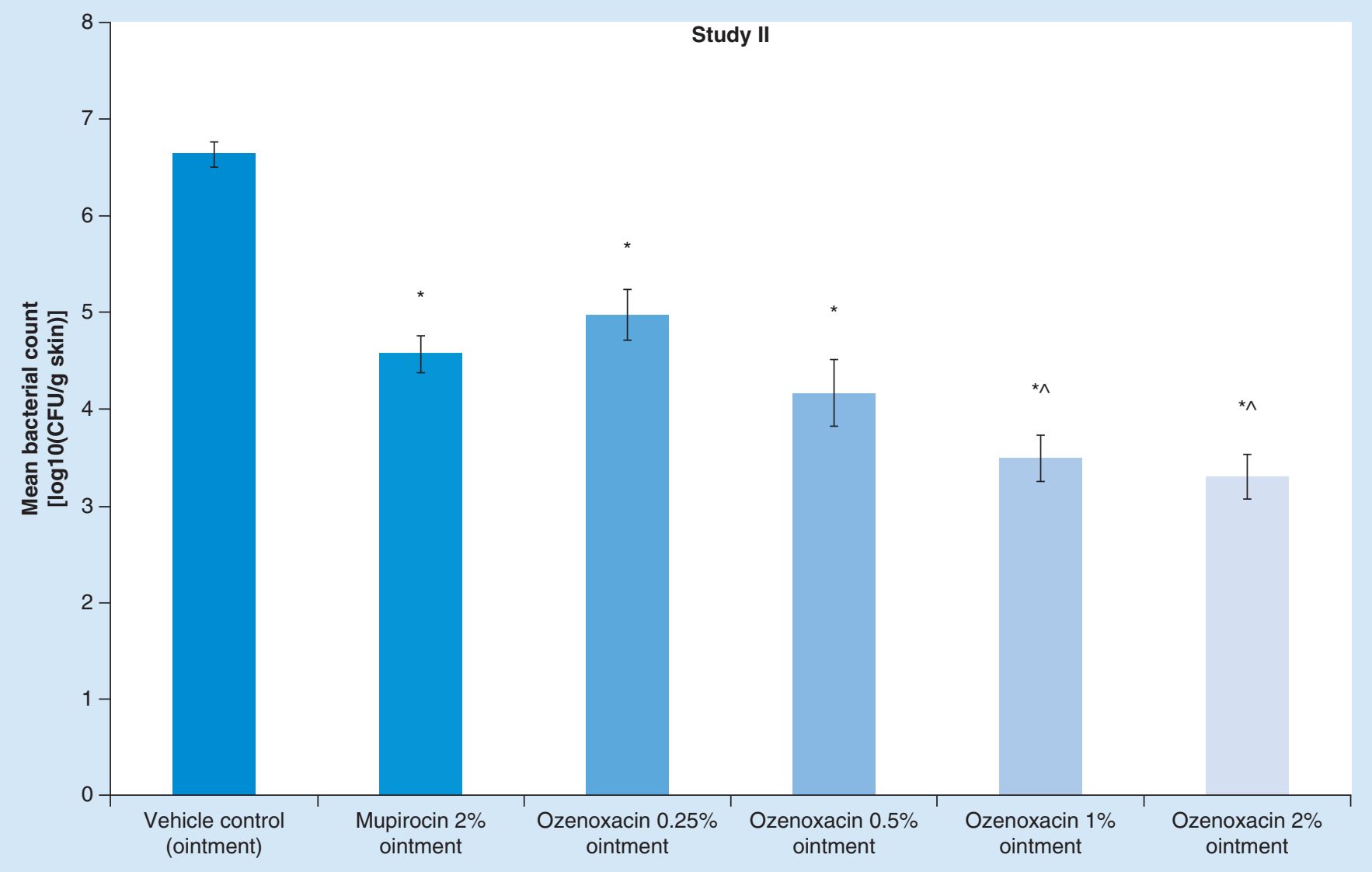

Figure 2. Mean bacterial counts in mice treated with ozenoxacin $(0.25,0.50,1$ or $2 \%)$, mupirocin $2 \%$ or vehicle control ointment administered once (study II).

*Tukey's HSD test $p<0.05$ for comparison of treatment groups with vehicle control.

${ }^{\wedge}$ Tukey's HSD test $p<0.05$ for comparison of 1 and $2 \%$ ozenoxacin ointment with $2 \%$ mupirocin ointment.

CFU: Colony-forming unit.

CLED- $\mathrm{MgCl}_{2}$ agar). Although $0.5 \%$ ozenoxacin ointment was less active than $1 \%$ or $2 \%$ ozenoxacin ointment, there was no statistically significant difference between groups.

Analyses of post-treatment skin samples showed that the only group in which no bacteria were recovered in skin samples was mice treated with $2 \%$ ozenoxacin $(6 / 15)$. In mice treated with $2 \%$ mupirocin or $0.25 \%$ ozenoxacin, there were no animals in which no $S$. aureus growth was detected in post-treatment skin samples. On the other hand, in groups of mice treated with 0.5 and $1 \%$ ozenoxacin ointments, a few animals each were detected without colonies growth ( 3 of 15 and 2 of 15 , respectively) in skin samples within the zone of infection (Table 2).

No adverse local effects were observed after application of ozenoxacin treatment (0.25-2\%). Although both 1 and $2 \%$ ozenoxacin formulations demonstrated good efficacy, the ozenoxacin $1 \%$ formulation was selected for continued product development.

Study III: comparison of the antibacterial activity of ozenoxacin (1\%) ointment \& cream with retapamulin (1\%) \& mupirocin $(2 \%)$ ointments in a mouse model of S. aureus dermal infection

Two formulations of ozenoxacin $1 \%$ (ointment and cream), and $1 \%$ retapamulin and $2 \%$ mupirocin ointments, were evaluated following single administration and compared with vehicle control ointment.

In the placebo group, mean $\pm \mathrm{SEM} \log _{10}(\mathrm{CFU} / \mathrm{g}$ skin) counts of $7.26 \pm 0.144$ were obtained following plating on CLED agar. In the mupirocin $2 \%$ ointment group (positive control), $\log _{10}(\mathrm{CFU} / \mathrm{g}$ skin) counts were $5.17 \pm 0.189$ after plating on CLED-AC. In the retapamulin $1 \%$ ointment group, $\log _{10}$ (CFU/g skin) counts were 


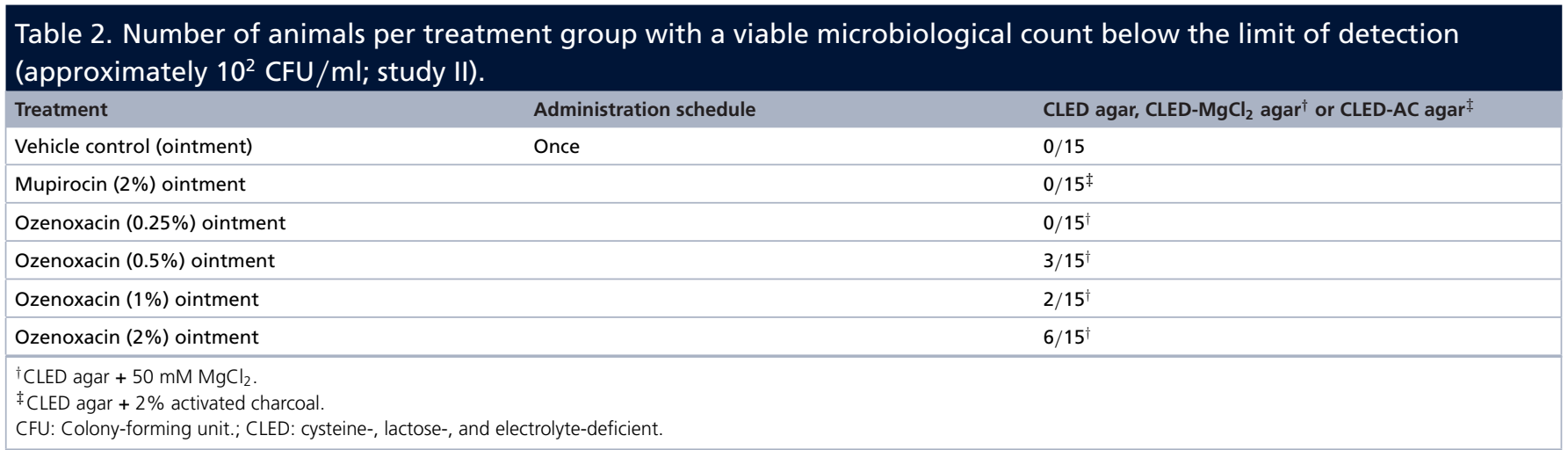

$4.95 \pm 0.244$ after plating on CLED-AC. In two ozenoxacin $1 \%$ batches (ointment and cream), $\log _{10}(\mathrm{CFU} / \mathrm{g}$ skin) counts were $3.39 \pm 0.242$ and $3.82 \pm 0.206$, respectively, following plating on CLED- $\mathrm{MgCl}_{2}$.

A one-way analysis of variance showed that there was a significant difference $(\mathrm{p}<0.01)$ in the means of the treatment and control groups. Post hoc analysis using the Student-Newman-Keuls test showed that both batches of ozenoxacin $1 \%$ produced significant reductions in bacterial counts $(\mathrm{p}<0.05)$ when plated on CLED or CLED- $\mathrm{MgCl}_{2}$ agar, but no differences were observed between the two ozenoxacin $1 \%$ formulations. Similarly, both retapamulin and mupirocin had statistically significant lower microbiological counts compared with the vehicle control group, with no significant differences found between these two treatment groups. There were statistically significant differences between groups treated with ozenoxacin $1 \%$ formulations and groups treated with retapamulin $1 \%$ and mupirocin $2 \%$ ointment (Student-Newman-Keuls test; $\mathrm{p}<0.05$; Figure 3).

In this study, the vehicle control group showed the most homogeneous results, followed by groups treated with $1 \%$ ozenoxacin cream and $2 \%$ ointment mupirocin, which is consistent with results of the previous studies. Both $1 \%$ ozenoxacin and $1 \%$ retapamulin ointments showed somewhat more variability, but were also in the line with the previous studies (studies I and II).

In addition, groups of animals treated with ozenoxacin had lower counts of $S$. aureus in the lesion areas than those treated with retapamulin and mupirocin ointments. Both groups treated with $1 \%$ ozenoxacin formulations showed statistically significant differences in the decrease of infectivity compared with mice treated with either $2 \%$ mupirocin ointment or $1 \%$ retapamulin ointment (Student-Newman-Keuls test; $\mathrm{p}<0.05$ ).

Mice treated once with either ozenoxacin batch showed significantly lower growth of $S$. aureus compared with mice treated with $1 \%$ retapamulin and $2 \%$ mupirocin ointments (Figure 3). Bacterial eradication rates were 47 and $53 \%$ with ozenoxacin ointment and cream batches, compared with $31 \%$ with retapamulin ointment and $28 \%$ with mupirocin ointment (Figure 4).

No adverse local effects were observed after application of the treatments, and both ozenoxacin formulations showed a homogeneous and rapid antibacterial action.

\section{Discussion}

During the development of ozenoxacin, a nonfluorinated quinolone for the topical treatment of impetigo, three studies in animals were conducted in order to select the best formulation to start the human phase of development.

The rodent dermal infection model to investigate the efficacy of topical antibiotics on skin lesions is a wellestablished method, which has been used in mice to investigate the efficacy of amoxicillin, amoxicillin-clavulanic acid or mupirocin against experimentally induced skin infections of $S$. aureus and Streptococcus pyogenes [6,18].

Here, mice models of dermal infection were used to assess different concentrations and formulations of topical ozenoxacin, and to compare its efficacy with that of mupirocin and retapamulin ointments, using an inactive ointment as a negative vehicle control. Comparison of five different formulations (ointment, gels and creams) of topical $1 \%$ ozenoxacin in mice showed minor differences after a single application.

In study I, a comparison of five different $1 \%$ ozenoxacin formulations showed that the most effective formulations were cream and ointment, with $1 \%$ ozenoxacin ointment (batch 1) ranked the highest following Tukey's HDS analysis.

In study II, a comparison of ozenoxacin ointments with concentrations ranging from 0.25 to $2 \%$ showed that the most effective concentrations for significantly reducing bacterial cell counts were 1 and $2 \%$. 


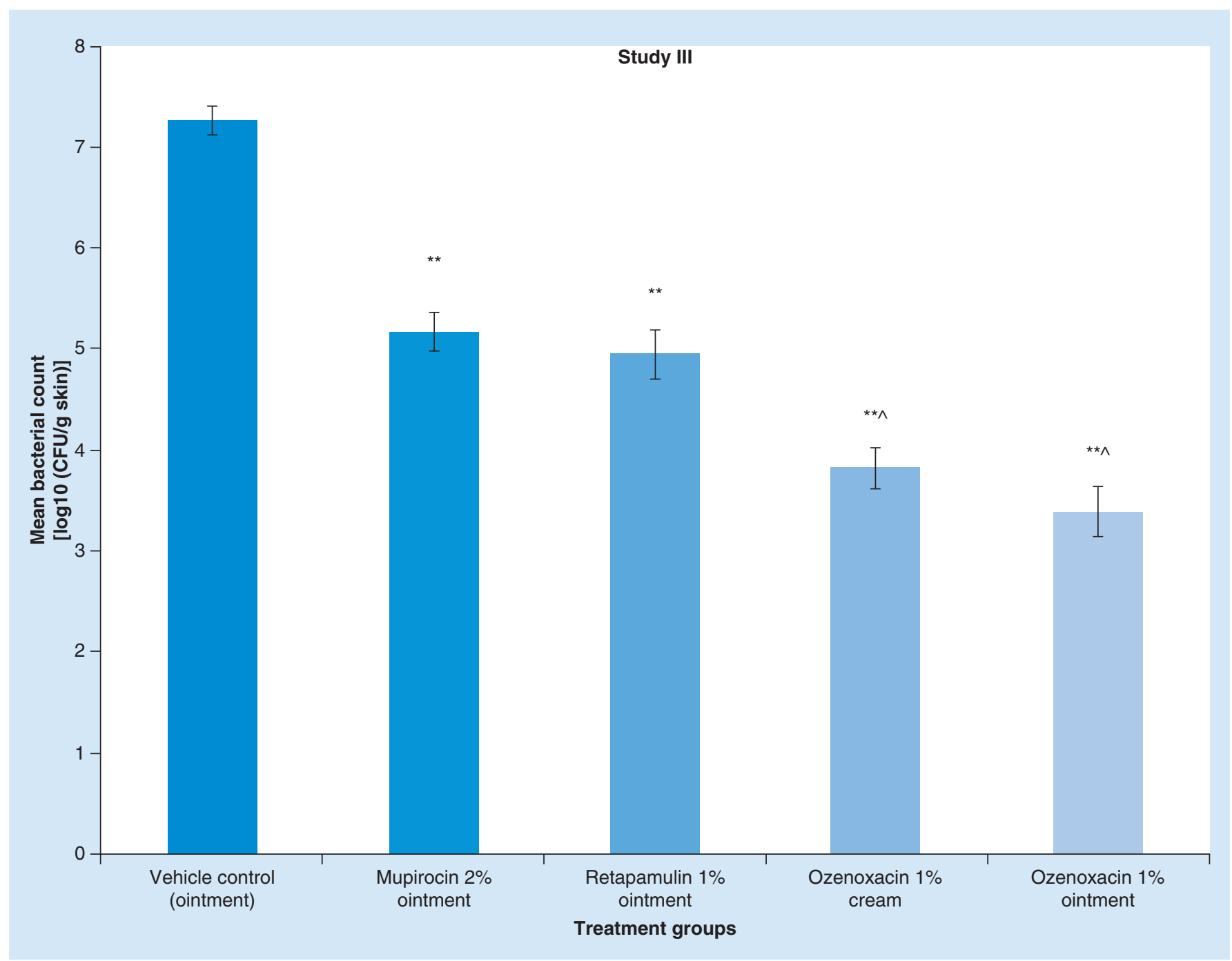

Figure 3. Mean bacterial counts in mice treated with ozenoxacin (1\%) cream or ointment, mupirocin $2 \%$ or retapamulin (1\%) ointment, or vehicle control,administered once (study III).

**Student-Newman-Keuls test $\mathrm{p}<0.05$ for comparison of treatment groups with vehicle control.

$\wedge$ Student-Newman-Keuls test $p<0.05$ for comparison of $1 \%$ ozenoxacin formulations with $2 \%$ mupirocin ointment and $1 \%$ retapamulin ointment.

CFU: Colony-forming unit.

Direct comparison of two batches of $1 \%$ ozenoxacin ointment and cream with $1 \%$ retapamulin and $2 \%$ mupirocin ointments (study III) showed that both ozenoxacin formulations had superior efficacy after a single application with significantly higher bacterial eradication rates (47 and 53\%) than retapamulin (31\%) and mupirocin (28\%). The results support those reported in a Phase III trial of impetigo, in which ozenoxacin produced a more rapid microbiological clearance than retapamulin [13].

\section{Conclusion}

All animal groups treated with antibiotic formulations (ozenoxacin, retapamulin and mupirocin) showed reduced infectivity in mice dermally infected with $S$. aureus compared with vehicle control groups. The efficacy of ozenoxacin formulations was higher than that observed with retapamulin or mupirocin, especially with the selected final formulation, ozenoxacin $1 \%$ cream.

As cream formulations are preferred by patients for their emollient properties and are cosmetically more convenient and better accepted, the $1 \%$ cream formulation was chosen for clinical development. 


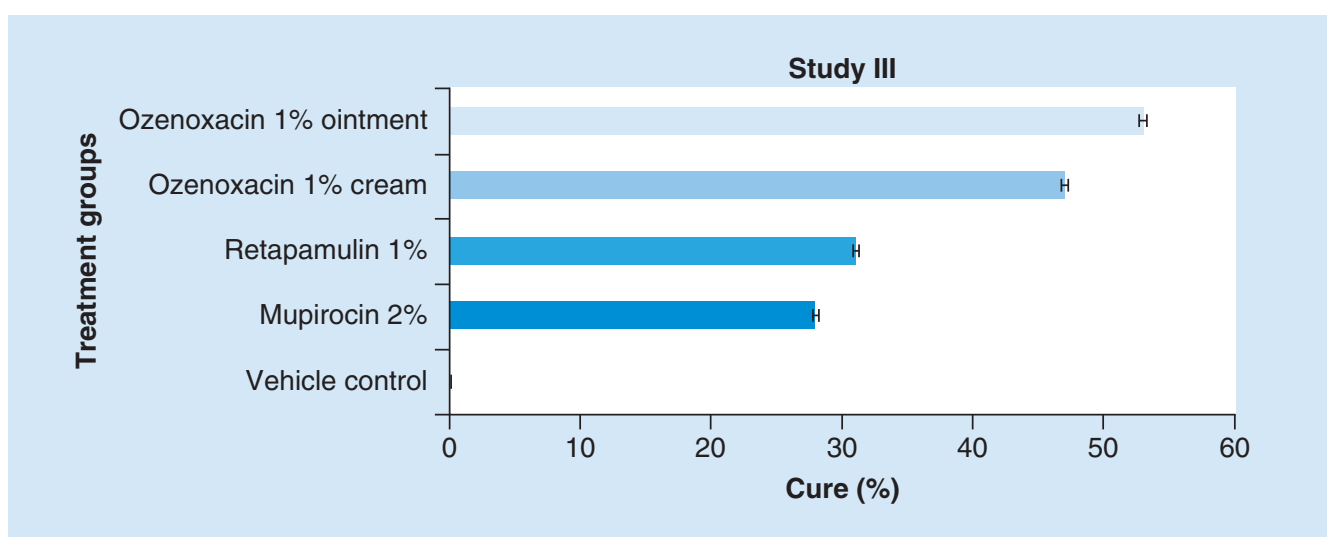

Figure 4. Bacterial eradication rates of mice treated with ozenoxacin (1\%) cream or ointment, mupirocin ( $2 \%)$ or reptamulin (1\%) ointment, or vehicle control, administered once (study III). Bacterial eradication rate is the relative $\log _{10}$ transformation of CFU counts per gram of skin for control and test treatments.

\section{Future perspective}

The ozenoxacin 1\% cream formulation selected in this study has been developed for clinical use, with demonstrable efficacy in Phase III clinical trials for the treatment of impetigo [13,14]. Ozenoxacin produced a superior clinical and microbiological response when compared with placebo [13,14], and had similar efficacy to retapamulin but showed more rapid microbiological clearance than retapamulin [13]. In Japan, ozenoxacin is used for the treatment of acne vulgaris $[20,21]$.

\section{Executive summary}

- A preclinical study using a mice model of Staphylococcus aureus dermal infection compared different concentrations and formulations of topical ozenoxacin, with vehicle control, mupirocin and retapamulin ointments.

- In a mouse model of $S$. aureus dermal infection different formulations and/or concentrations of ozenoxacin were compared with $1 \%$ retapamulin and $2 \%$ mupirocin ointments.

- Each of five different $1 \%$ ozenoxacin formulations (one ointment, two gels and two creams) significantly reduced the bacterial count compared with negative vehicle control, with no significant differences between formulations. No significant differences were found between any of the $1 \%$ ozenoxacin formulations and $2 \%$ mupirocin ointment. The most effective formulations were $1 \%$ ozenoxacin cream and ointment (Tukey's honest significant difference [HSD] test; $p<0.05)$.

- Ozenoxacin ointments $(0.25,0.5,1$ and $2 \%)$ and $2 \%$ mupirocin ointment (positive control) produced statistically significant reductions $(p<0.05)$ in bacterial growth compared with vehicle control ointment. Mice treated with 1 or $2 \%$ ozenoxacin ointment showed statistically significant reductions (Tukey's HSD test; $p<0.05$ ) in counts compared with the $2 \%$ mupirocin ointment group; a clear dose-effect relationship was found with ozenoxacin at the concentrations used, with 1 and $2 \%$ ozenoxacin ointments being the most effective.

- Mice treated once with $1 \%$ ozenoxacin ointment or cream showed significantly lower growth of $S$. aureus compared with mice treated with $1 \%$ retapamulin and $2 \%$ mupirocin ointments. Bacterial eradication rates were 47 and 53\% with ozenoxacin ointment and cream batches respectively, compared with $31 \%$ with retapamulin ointment and $28 \%$ with mupirocin ointment.

- No adverse local effects were observed after application of ozenoxacin formulations which showed a homogeneous and rapid antibacterial action.

- All S. aureus dermally infected animal groups treated with antibiotic formulations (ozenoxacin, retapamulin and mupirocin) showed reduced infectivity compared with vehicle control groups. The efficacy of ozenoxacin formulations was higher than that observed with retapamulin or mupirocin, especially with the selected final formulation, ozenoxacin $1 \%$ cream. 
y Desarrollo Aplicado, SAL (CIDASAL) at the time the studies were performed. I Zsolt and F D'Aniello are current employees of Ferrer Internacional. The authors have no other relevant affiliations or financial involvements with any organization or entity with a financial interest in or financial conflict with the subject matter or materials discussed in the manuscript apart from those disclosed.

Writing assistance was provided by Content Ed Net (Madrid, Spain) with funding provided by Ferrer International SA (Barcelona, Spain).

\section{Ethical conduct of research}

This study was completed in accordance with Organisation for Economic Co-operation and Development guidelines [22].

\section{References}

1. Yamakawa T, Mitsuyama J, Hayashi K. In vitro and in vivo antibacterial activity of T-3912, a novel non-fluorinated topical quinolone. J. Antimicrob. Chemother. 49(3), 455-465 (2002).

2. Tarragó C. Caracterización y desarrollo de ozenoxacino: una quinolona no fluorada [Characterization and development of ozenoxacin: a non-fluorinated quinolone]. Tesis doctoral Microbiologia Mèdica. Universitat de Barcelona (2011). http://hdl.handle.net/10803/404326

3. López $\mathrm{Y}$, Tato M, Espinal $\mathrm{P}$ et al. In vitro activity of ozenoxacin against quinolone-susceptible and quinolone-resistant Gram-positive bacteria. Antimicrob. Agents Chemother. 57(12), 6389-6392 (2013).

4. Tato M, López Y, Morosini MI et al. Characterization of variables that may influence ozenoxacin in susceptibility testing, including MIC and MBC values. Diagn. Microbiol. Infect. Dis. 78, 263-267 (2014).

5. López Y, Tato M, Espinal P et al. In vitro selection of mutants resistant to ozenoxacin compared with levofloxacin and ciprofloxacin in Gram-positive cocci. J. Antimicrob. Chemother. 70(1), 57-61 (2015).

6. Boon RJ, Beale AS. Response of Streptococcus pyogenes to therapy with amoxicillin or amoxicillin-clavulanic acid in a mouse model of mixed infection caused by Staphylococcus aureus and Streptococcus pyogenes. Antimicrob. Agents Chemother. 31, 1204-1209 (1987).

7. García-Castillo M, Tato M, García-Alonso F et al. Ozenoxacin antibacterial activity against worldwide Gram-positive bacteria causing skin and soft tissue infections. Presented at: 26th European Congress of Clinical Microbiology and Infectious Diseases (ECCMID), 9-12 April, Amsterdam, The Netherlands (2016).

8. Cantón R, Morrissey I, Vila J et al. Comparative in vitro antibacterial activity of ozenoxacin against Gram-positive clinical isolates recovered from skin and soft tissue infections. Future Microbiol. 13(6s), 3-19 (2018).

9. Pereira LB. Impetigo - review. An. Bras. Dermatol. 89(2), 293-299 (2014).

10. Sladden MJ, Johnston GA. Common skin infections in children. Br. Med. J. 329, 95-99 (2004).

11. Hartman-Adams H, Banvard C, Juckett G. Impetigo: diagnosis and treatment. Am. Fam. Physician 90, 229-235 (2014).

12. Koning S, van der Sande R, Verhagen AP et al. Interventions for impetigo. Cochrane Database Syst. Rev. 1, CD003261 (2012).

13. Gropper S, Albareda N, Chelius $\mathrm{K}$ et al. Ozenoxacin 1\% cream in the treatment of impetigo: a multicenter, randomized, placebo- and retapamulin-controlled clinical trial. Future Microbiol. 9(9), 1013-1023 (2014).

14. Albareda $\mathrm{N}$, Zeichner J, Rosenberg $\mathrm{N}$ et al. A randomized vehicle-controlled trial to assess the efficacy, safety, and tolerability of ozenoxacin 1\% cream in 412 patients 2 months and older with impetigo. J. Cutan. Med. 1, s103 (2017).

15. Medicines and Healthcare products Regulatory Agency (MHRA). Ozadub $10 \mathrm{mg} / \mathrm{g}$ cream: ozenoxacin summary of product characteristics (SPC) (2017). www.mhra.gov.uk/spc-pil/index.htm?subsName=OZENOXACIN\&pageID=SecondLevel

16. US Food and Drug Administration (FDA). Xepi (ozenoxacin) Cream. Summary Review (2017). www.accessdata.fda.gov/drugsatfda_docs/nda/2017/208945Orig1s000TOC.cfm

17. Health Canada. OZANEX ${ }^{T M}$, ozenoxacin cream $1 \% w / w$. Product Monograph. (2017). https://health-products.canada.ca/dpd-bdpp/dispatch-repartition.do

18. Gisby J, Bryant J. Efficacy of a new cream formulation of mupirocin: comparison with oral and topical agents in experimental skin infections. Antimicrob. Agents Chemother. 44, 255-260 (2000).

19. Rittenhouse S, Singley C, Hoover J et al. Use of the surgical wound infection model to determine the efficacious dosing regimen of retapamulin, a novel topical antibiotic. Antimicrob. Agents Chemother. 50(11), 3886-3888 (2006).

20. Nakajima A, Ikeda F, Kanayama S et al. Antimicrobial activities of ozenoxacin against isolates of propionibacteria and staphylococci from Japanese patients with acne vulgaris. J. Med. Microbiol. 65, 745-750 (2016).

21. Kanayama S, Okamoto K, Ikeda F et al. Bactericidal activity and post-antibiotic effect of ozenoxacin against Propionibacterium acnes. J. Infect. Chemother. 23(6), 374-380 (2017).

22. OECD. Guidance Document on the Recognition, Assessment and Use of Clinical Signs as Human Endpoints for Experimental Animals Used in Safety Evaluation (2002). www.oecd-ilibrary.org/environment/guidance-document-on-the-recognition-assessment-and-use-of -clinical-signs-as-human-endpoints-for-experimental-animals-used-in-safety-evaluation_9789264078376-en 